\title{
Preliminary Study: Application of Spot-mapping Technique for Estimating the Size of Oriental Magpie Robin Cospychus saularis (Aves: Muscicapidae) Territories in Universiti Malaysia Sarawak (UNIMAS)
}

\author{
KATHLEEN MICHELLE LUKING*, DENCY FLENNY GAWIN* \& JESSIE MENTIE
}

\author{
Faculty of Resource Science and Technology, Universiti Malaysia Sarawak, 94300 Kota Samarahan, Sarawak, \\ Malaysia \\ *Corresponding authors: kathleenluking@gmail.com; agdflenny@unimas.my
}

\begin{abstract}
Breeding territoriality plays a role in determining the reproduction outcome of many passerines species. The spotmapping was used to estimate the breeding territory size of a territorial male of Oriental Magpie robin (Cospychus saularis) at Dahlia College, Universiti Malaysia Sarawak which is located within Kota Samarahan. It was conducted by mapping the song perching locations established by a marked male. The breeding territory size of the male was estimated to be 0.78 hectares. The data analysis was done using Minimum Convex Polygon (MCP) which was constructed by using Google Earth Pro software. Study on breeding territory size of this bird species is crucial to understand more regarding the breeding behaviour of this species. Data on the behavior of this species could be used for future studies of this bird in Borneo.
\end{abstract}

Keywords: Oriental Magpie Robin, breeding territory size, spot-mapping, Minimum Convex Polygon

Copyright: This is an open access article distributed under the terms of the CC-BY-NC-SA (Creative Commons Attribution-NonCommercialShareAlike 4.0 International License) which permits unrestricted use, distribution, and reproduction in any medium, for non-commercial purposes, provided the original work of the author(s) is properly cited.

\section{INTRODUCTION}

The Oriental Magpie robin (Copsychus saularis) is a passerine bird from family Muscicapidae (Myers, 2009). It is a common species in Malaysia Borneo (Phillipps, 2011). It is widely distributed in Indian Subcontinent, S. China, SE Asia, Sumatra, Java, Bali and Philippines, excluding Palawan (Lim et al., 2010; Myers, 2009). Morphologically, this open-area species can be characterised by its possession of prominent black and white plumage colours; black bill, grey legs, and has a long tail. Both male and female has similar morphological features, but they can easily be identified by its differences in their plumage colours. The male has black upper parts and throat, white under parts and side of the tail (Figure 1); while for the female, the black colour of male is replaced with grey colour (Figure 2). There are three sub-species recorded in Borneo, which are C. s. musicus, C. s. adamsi, and $C$. s. pluto. This species can be found in cultivated areas, woodland, and areas close to human settlements (Koli, 2014). Their foods consist of invertebrates like cockroaches, dragonflies, and praying mantis larvae and small vertebrates like house geckos (Sreekar, 2010).

C. saularis is a secondary cavity nester; which both male and female build up their nests in natural cavities like tree holes and artificial cavities like nest boxes or any holes in a building (Singh, Bhatt, Sethi \& Dadwal, 2016). Being classified as a territorial species, the male of $C$. saularis utters its territorial song to establish their own territory and attract females during mating season (Bhatt, Kumar, Singh \& Payne, 2000; Catchpole \& Slater, 2008; Wanniarachchi \& Wijesundara, 2016). It also maintains its own territory, which is known as territoriality. This act will occur when the male individual acts defensively toward any intruders within a specific area of which it fully uses its territorial area for nesting activities, obtaining food resources, and mating (Brown, 1964; Odum \& Kuenzler, 1955). The territorial area might consist of a part or entire space used by the male individual to carry out its daily activities during mating and breeding season (Catchpole \& Slater, 2008; Wanniarachchi \& Wijesundara, 2016).

This study focuses on estimating the territorial size of a male $C$. saularis as well as collecting data on one pair daily activities during their breeding season for future researches. Based on the previous studies, the Magpie robins are constantly threatened by both intraspecific as well as introduced species like Asian Glossy starling (Aplonis panayensis) and Common Myna (Acridotheres tristis) (Singh et al., 2016). In addition, the scarcity of tree cavities caused by habitat degradation and urbanization has induced the fights for nesting sites between those three species, which the introduced species are more dominant compared to C. saularis (Bhatt, Sethi, Kumar \& Singh, 2014). 


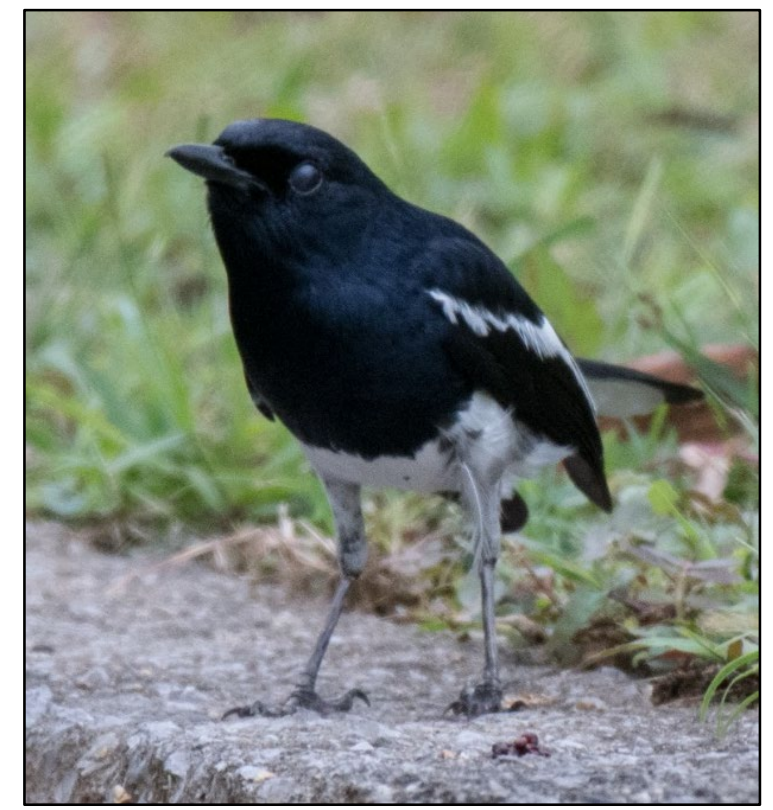

Figure 1. A male of C. saularis was found hoping on the ground. Photo credit: Jason (2018).

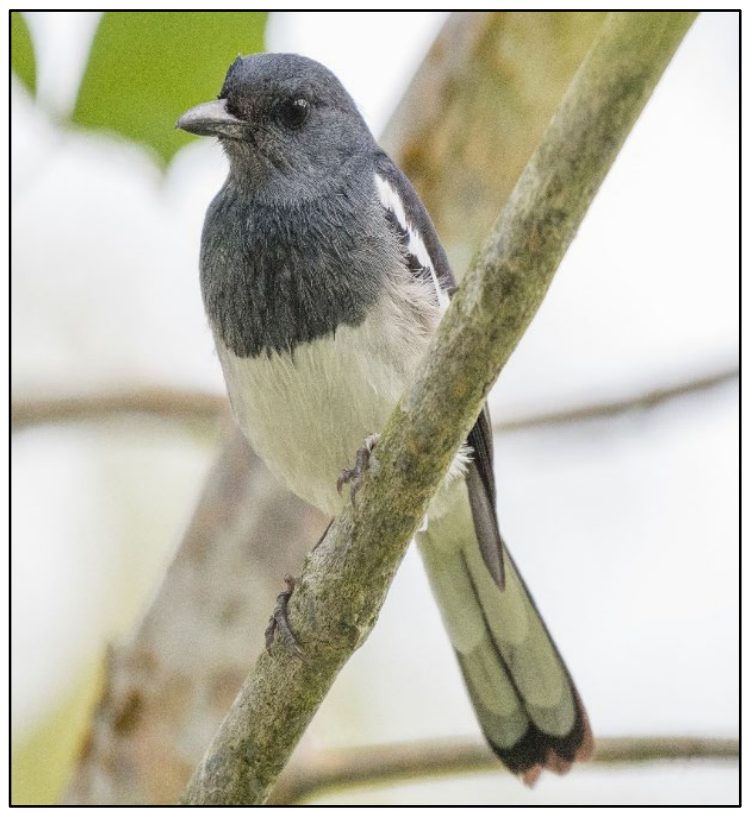

Figure 2. A female of $C$. saularis was found perching on a branch of tree. Photo credit: Jason (2018).

\section{MATERIAL \& METHODS}

\section{Study Sites}

The study site was located at Dahlia College, Universiti Malaysia Sarawak (1²7'34" N, 110²9'56" E) within Kota Samarahan Division (Figure 3). The selection of this site is due to easy accessibility and the college itself is near to UNIMAS Sarawak Golf Club boundaries which were planted with many trees.

\section{Bird Trapping and Spot-Mapping}

A male $C$. saularis was captured by using mist nets. The bird was found nested in a cavity of Pulai tree species (Alstonia angustiloba) (Figure 4). Playback songs were used to attract this male bird (Najmi-Hanis, Puan, Zakaria \& Azhar, 2016). Once captured, the male was then marked with a unique combination of two colours plastic, leg bands for individual recognition. After the banded bird was released back to its habitat, the behaviour of the marked male bird was observed for approximately $10-20$ minutes. If the bird constantly picked the bands with its mouth after the 20 minutes, the bands would be removed. 


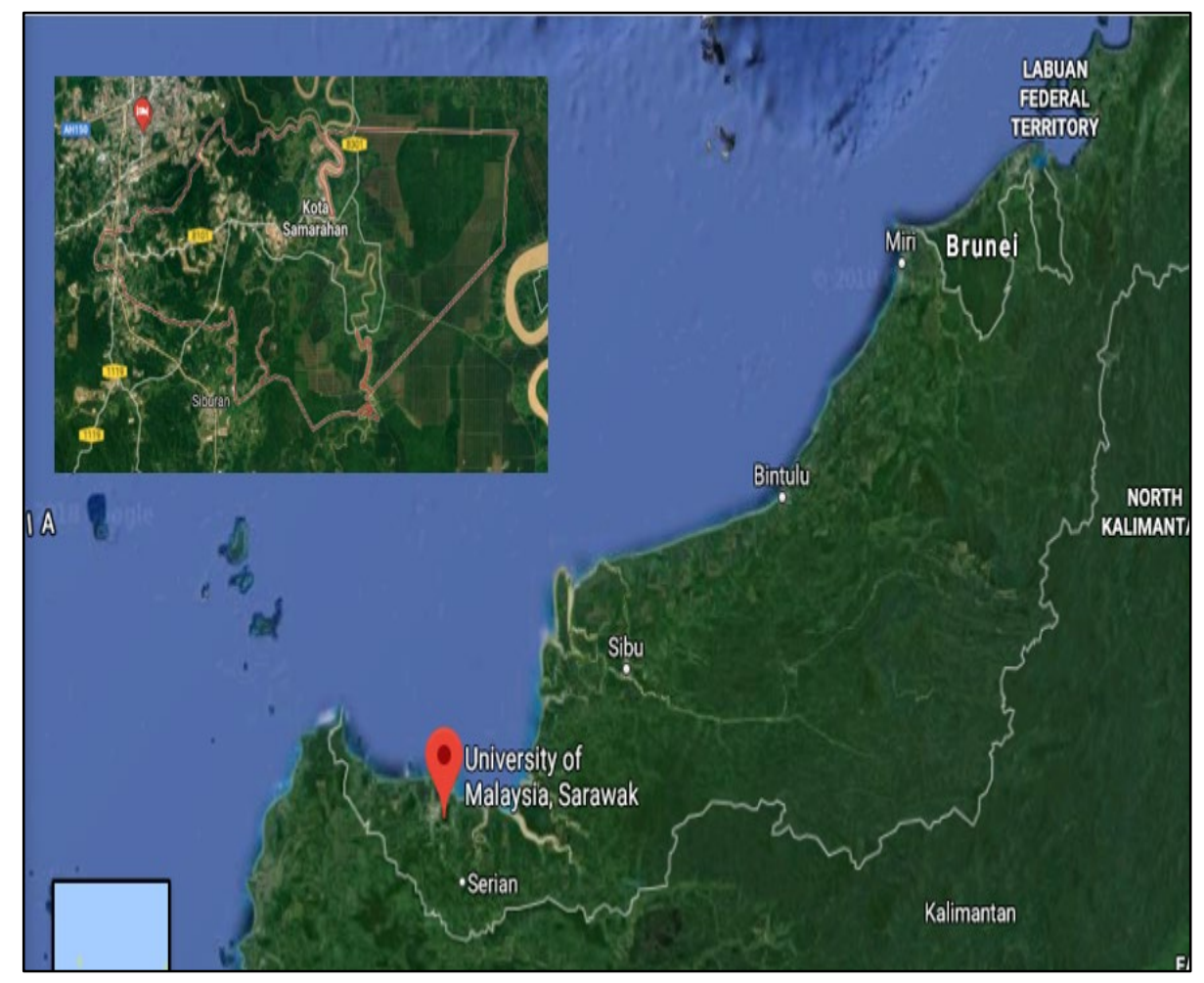

Figure 3. The map shows the location of studied area which is Dahlia College, UNIMAS by using Google Earth Pro software.

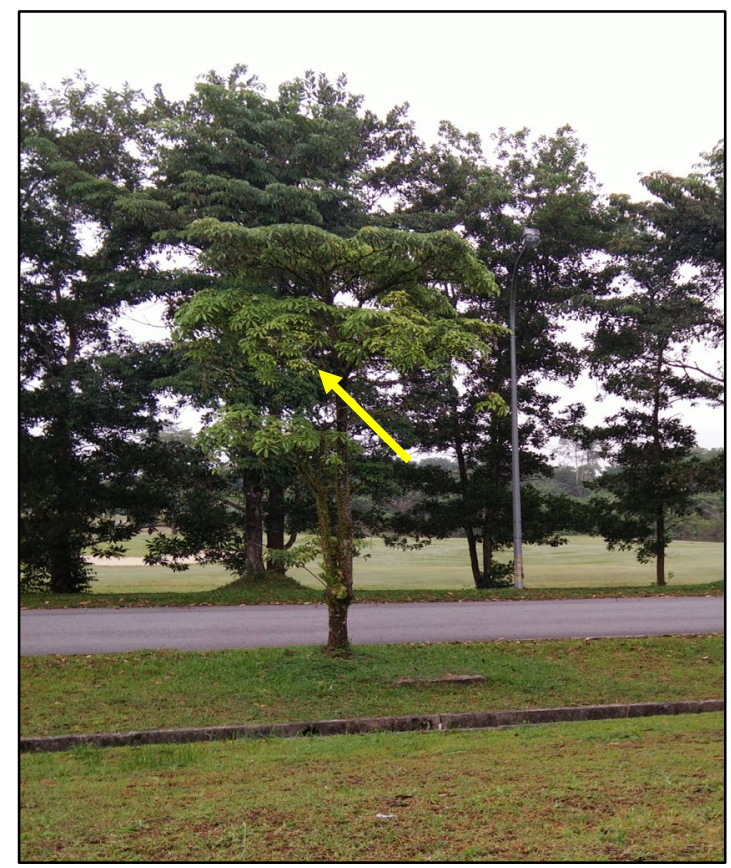

Figure 4. The bird was found nested in the hole (yellow arrow) of Pulai tree (Alstonia angustiloba). Photo credit: Kathleen (2018).

It is known that the breeding season of this species in UNIMAS begins at the end of December until mid-September (personal communication). However, due to time constraint, the spot-mapping was conducted from March 17 to April 15, 2018 which were still within the species breeding period. The spot-mapping can be used to calculate the song territory size of a passerine bird (Streby, Loegering \& Andersen, 2012), estimate the number of breeding pairs in an area by accurately counting the number of territorial males (Franzreb, 1976), delineate core breeding territories (Frantz et al., 2016), and determine the density of a population of a songbird species within the area 
(Rimmer, Atwood, McFarland \& Nagy, 1996). Observation periods were done during non-raining days, while the sampling hours were in the morning (0630 - 1030 hours) and afternoon (1630 - 1830 hours) daily. It was done by walking systematically through the study site, stopped when a song from the male bird was heard or it was observed landing on a branch tree or any perching locations through a pair of binoculars or naked eyes. Once the marked male had been identified, it would be followed 30 - 60 minute of sampling period (Barg, Jones \& Robertson, 2005). If the bird disappeared from our view, or could not be located within 15 minutes, the walking activity would be continued on. As soon as the male bird moved on to other perch location, a handheld Garmin GPSMAP 78S Marine Handheld Global Positioning System (GPS) unit was used to record the coordinate of the previous perching location. The spots or perching locations which were collected after many days were then be combined to identify the space used by the marked male $C$. saularis.

\section{Data Analysis}

The perching locations of the marked male bird were plotted by using Google Earth Pro software. The collected data consisted of coordinates of the perching locations, times, and activities of the marked male bird during observation period. The territory size of the marked male bird was estimated using the non-parametric minimum convex polygon (MCP) method. It is used to delineate space used by the animal for its daily activities (Kenward $\&$ Hodder, 1998). The disadvantage of MCP is, it is sensitive to outliers and unable to show the core area used by an animal (Najmi-Hanis et al., 2016). Despite these, MCP is internationally accepted technique to be used to estimate the breeding territory size due to its simplicity (Burgman \& Fox, 2006). Using this MCP technique, all the outermost coordinate points collected from the studied site at Dahlia College were connected and the territorial space belonged to the marked male of $C$. saularis could be estimated.

\section{RESULTS \& DISCUSSION}

There were 45 perching locations recorded throughout this study within Dahlia College, where the red spot indicated all the perching locations while the yellow-pinned symbol indicated the nest of the marked male bird together its mate (Figure 5).

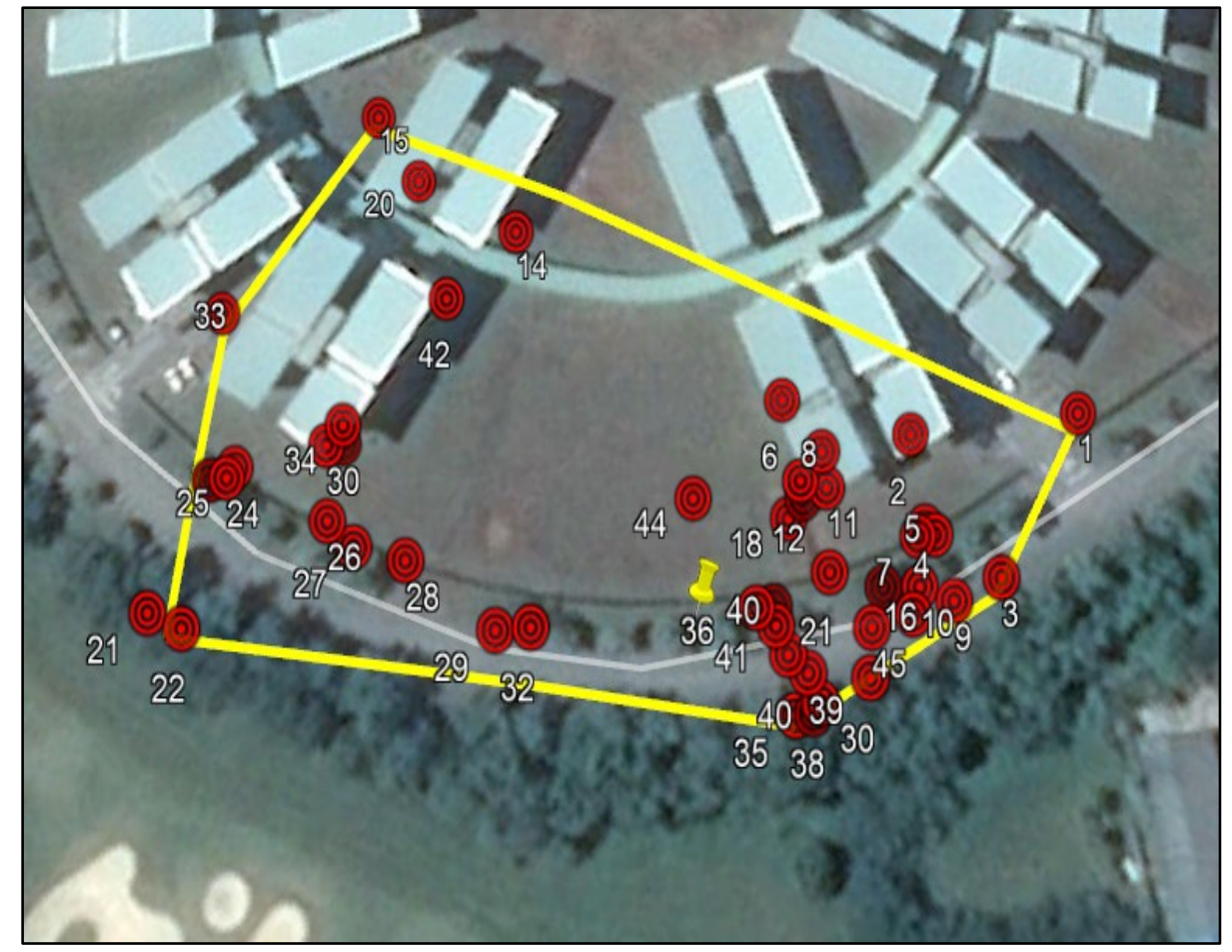

Figure 5. The estimated breeding territory size of the banded male C. saularis in Dahlia College, UNIMAS constructed using the Minimum Convex Polygon (MCP).

This bird was found nested in the cavity of Pulai tree species (Alstonia angustiloba) (Figure 4). The nest was found during the middle of the incubation period. This pair had a clutch of two eggs the moment of the nest was firstly discovered. One of the eggs had been hatched and the nestling grew to become a female juvenile while the other egg was still in the incubation stage. For this species, only the female incubates the eggs while the male guards the area by perching near to its nest (Singh et al., 2016). The male was also frequently been seen to feed both juvenile and female in the nest. Being an insectivore species, it was observed that the male usually fed them 
with insects like cockroaches and grasshoppers. Most of the time, the marked male bird was found perching and singing within its territorial area. Males of $C$. saularis spend about $47-51 \%$ of their diurnal time singing and calling (Wanniarachchi \& Wijesundara, 2016).

The estimated territory size belonged to this marked male bird was 0.78 hectares. The territory size was larger compared to the study done by Singh et al. (2016) which was ranged from 0.17 to 0.45 hectares. The differences might be due to the number of males which were being observed during the whole sampling period. There were about 21 territorial males observed by Singh et al. (2016) within four years (2011-2014) study, while only one marked male individual was observed within one-month period in this present study. There is a possibility that a long-term sampling may lead to different results as observers can have more informative data on bird behaviours and nesting success if compared to a short-term sampling (Yap, 2003). In addition, the territory sizes of this bird species may be different from one year to another (Yap, 2003).

Another factor that need to be considered is the effectiveness applying the spot-mapping method. This method is preferable to be applied during breeding season. Franzreb (1976) stated that breeding season is the only time birds utter territorial songs and guard their territories from any intruders. During the data sampling, the observed pair birds were in the middle of incubating their one egg and provisioning one nestling. However, the female did not complete incubating the last egg and it went missing from the nest probably it had been taken by a predator. Hence, the data sampling could not be achieved for the whole breeding duration for this pair, and this might affect the breeding territory size of the marked male bird.

\section{CONCLUSION}

The spot-mapping technique is one of the methods that can be applied to estimate the breeding territory size of a male of $C$. saularis and any other passerine bird species. The obtained data can be used to understand the breeding behaviours of this species during breeding season. In future, it is recommended to use the advanced radio telemetry instead of the spot-mapping technique as the former method can estimate three times larger of a territorial size compared to the later technique. By using the radio telemetry, the used space by the studied bird species within its breeding territory area can be covered more. In addition, it is recommended that the study area shall be expanded into the Samarahan Country Club, which is located next to UNIMAS. Based on our observations, most of the individuals of $C$. saularis were observed to fly into the area. Expansion of the study area in future, may increase the accuracy of estimation of the space used by this songbird species within Kota Samarahan.

\section{ACKNOWLEDGEMENT}

The research for this paper was financially supported by the UNIMAS, grant no. F07(S161)/1189/2014(26). In developing this manuscript, we have received helpful input from Zahran Manshor, Charlie Laman, other lecturers and third year students of Batch 2016 in Animal Resource Science Management Program, UNIMAS.

\section{REFERENCES}

Barg, J. J., Jones, J., \& Robertson, R. J. (2005). Describing breeding territories of migratory passerines: suggestions for sampling, choice of estimator, and delineation of core areas. Journal of Animal Ecology, 74(1), 139-149.

Bhatt, D., Kumar, A., Singh, Y., \& Payne, R. B. (2000). Territorial songs and calls of the oriental magpie robin (Copsychus saularis). Current Science, 78, 722-728.

Bhatt, D., Sethi, V. K., Kumar, A., \& Singh, A. (2014). Some notes on the breeding behaviour of the Oriental Magpie Robin (Copsychus saularis) from Uttarakhand, India. Journal of Sustainability Science and Management, 9(1), 112-119.

Brown, J. L. (1964). The evolution of diversity in avian territorial systems. The Wilson Bulletin, 76(2), 160-169.

Burgman, M. A. \& Fox, J. C. (2006). Bias in species range estimates from minimum convex polygons: implications for conservation and options for improved planning. Animal Conservation, 6(1), 19-28.

Catchpole, C. K., \& Slater, P. J. B. (2008). Bird Song: Biological Themes and Variations (2 ${ }^{\text {nd }}$ ed.). New York, US: Cambridge University Press.

Frantz, M. W., Aldinger, K. R., Wood, P. B., Duchamp, J., Nuttle, T., Vitz, A., \& Larkin, J. L. (2016). Space and habitat use of breeding Golden-winged Warblers in the central Appalachian Mountains. In M. W. Frantz, K. R. Aldinger, P. Wood, J. Duchamp, T. Nuttle, A. Vitz, \& J. L. Larkin (Eds.), Studies in Avian Biology (pp. 8-94). Boca Raton, FL: CRC Press.

Franzreb, K. E. (1976). Comparison of variable strip transect and spot-map methods for censusing avian populations in a mixed-coniferous forest. Condor, 78(2), 260-262.

Kenward, R. E., \& Hodder, K. H. (1998). Red squirrels (Sciurus vulgaris) released in conifer woodland: the effects of source habitat, predation and interactions with grey squirrels (Sciurus carolinensis). Journal of Zoology, 244, 23-32. 
Koli, V. (2014). Morning territorial calls of male oriental magpie robin (Copsychus saularis). TAPROBANICA: The Journal of Asian Biodiversity, 6(1), 60-62.

Lim, H. C., Zou, F., Taylor, S. S., Marks, B. D., Moyle, R. G., Voelker, G., \& Sheldon, F. H. (2010). Phylogeny of magpie-robins and shamas (Aves: Turdidae: Copsychus and Trichixos): implications for island biogeography in Southeast Asia. Journal of Biogeography, 37(10), 1894-1906.

Myers, S. (2009). Birds of Borneo-Brunei, Sabah, Sarawak, and Kalimantan. Princeton, New Jersey: Princeton University Press.

Najmi-Hanis, Z., Puan, C. L., Zakaria, M., \& Azhar, B. (2016). Home range and activity patterns of Sunda scops owl in Peninsular Malaysia. Raffles Bulletin of Zoology, 64, 28-32.

Odum, E. P., \& Kuenzler, E. J. (1955). Measurement of territory and home range size in birds. The Auk, 72(2), 128-137.

Phillipps, Q. (2011). Phillipps' field guide to the birds of Borneo. Oxford, England: John Beaufoy Books.

Rimmer, C. C., Atwood, J. L., McFarland, K. P., \& Nagy, L. R. (1996). Population density, vocal behavior, and recommended survey methods for Bicknell's Thrush. The Wilson Bulletin, 108(4), 639-649.

Singh, A., Bhatt, D., Sethi, V. K., \& Dadwal, N. (2016). Nesting success of the oriental magpie robin Cospychus saularis in nest boxes and tree cavities. Wildlife Biology, 22(6), 277-283.

Sreekar, R. (2010). A study on the habits of oriental magpie robin Copsychus saularis. Indian Birds, 5(5), 152153.

Streby, H. M., Loegering, J. P., \& Andersen, D. E. (2012). Spot-Mapping Underestimates Song-Territory Size and Use of Mature Forest by Breeding Golden-Winged Warblers in Minnesota, USA. Wildlife Society Bulletin, $36(1), 40-46$.

Wanniarachchi, S., \& Wijesundara, C. S. (2016). The repertoire and structure of vocalisations of the southern magpie robin (Copsychus saularis ceylonensis). Ceylon Journal of Science, 45(3), 47-54.

Yap, C. A. M. (2003). A study of the changes in the range sizes of white-vented mynas in Singapore. Raffles Bulletin of Zoology, 51(1), 159-164. 